\title{
DISTRIBUSI DAN KELIMPAHAN IKAN KARANG FAMILI POMACENTRIDAE DI PERAIRAN TERUMBU KARANG DESA POOPOH KECAMATAN TOMBARIRI KABUPATEN MINAHASA
}

Distribution and Abundance of Coral Fishes the Family Pomacentridae in Coral Reef Waters Poopoh Village Sub-District Tombariri Minahasa Regency

\author{
Ari B Rondonuwu ${ }^{1}$, John L Tombokan ${ }^{1}$, Unstain NWJ Rembet ${ }^{1}$
}

\begin{abstract}
This study aims to determine the distribution and abundance of reef fish (families Pomacentridae) in coral reef waters of Poopoh village District Tombariri. This study was conducted at 3 stations. Data collected was done using visual census on the 50-meter transect line at 3 meters and 10 meters depths. In addition to revealing the number of species and abundance of individuals Pomacentridae, data analysis aimed to determine the community index. Based on the identification, obtained 41 species from 12 genera. 4 species has its presence in large numbers in all three observation stations, Chromis margaritifer, Pomacentrus mollucensis, Chrysiptera unimaculata, and the species with the largest number of individuals that is Chromis ternatensis. Based on depth, found 35 species with a total of 3863 individuals at a depth of 3 meters and 36 species at a depth of 10 meters with a total of 3810 individuals. Pomacentridae fish species diversity index ranged between 2.181-2.857. Dominance Index, are categorized low in the range of 0.081-0.197.
\end{abstract}

Keywords : coral fishes, Pomacentridae, coral reef, Poopoh

\begin{abstract}
ABSTRAK
Penelitian ini bertujuan untuk mengetahui distribusi dan kelimpahan ikan karang famili pomacentridae di perairan terumbu karang Desa Poopoh Kecamatan Tombariri. Penelitian dilakukan di 3 lokasi. Pengambilan data dilakukan dengan metode sensus visual pada transek garis sepanjang 50 meter, kedalaman 3 meter dan 10 meter. Selain mengungkapkan jumlah spesies dan kelimpahan individu Pomacentridae, analisis data diarahkan untuk mengetahui indeks komunitas. Berdasarkan hasil identifikasi, diperoleh 41 spesies yang berasal dari 12 genera. 4 spesies kehadirannya dalam jumlah yang besar di ketiga stasiun pengamatan yaitu, Chromis margaritifer, Pomacentrus mollucensis, Chrysiptera unimaculata, dan spesies dengan jumlah individu terbesar yaitu Chromis ternatensis. Berdasarkan kedalaman, ditemukan 35 spesies dengan total 3863 individu pada kedalaman 3 meter dan 36 spesies di kedalaman 10 meter dengan jumlah total 3810 individu. Indeks keanekaragaman spesies ikan Pomacentridae berkisar antara 2.181-2.857. Indeks dominasi, dikategorikan rendah pada kisaran 0.081- 0.197.
\end{abstract}

Kata kunci : ikan karang, Pomacentridae, terumbu karang, Poopoh

\footnotetext{
${ }^{1}$ Laboratorium Pengelolaan Wilayah Pesisir Terpadu, FPIK UNSRAT
} 


\section{PENDAHULUAN}

Di dalam ekosistem terumbu karang bisa hidup berbagai jenis organisme seperti ikan karang, moluska, krustasea, sponge, alga, lamun, dan biota lainnya (Dahuri dkk., 2004). Keberadaaan ikan karang erat kaitannya dengan ketersediaan sumberdaya terumbu karang sebagai habitat. Ikan karang Pomacentridae merupakan salah satu kelompok ikan karang yang hidup di daerah terumbu karang. Kelimpahan spesies maupun individu yang tinggi, corak warna yang bervariasi menjadikan kelompok ikan ini sebagai pelengkap keindahan panorama wilayah terumbu karang, dan menjadi salah satu obyek wisata bahari penyelaman.

Perairan pantai Desa Poopoh merupakan wilayah terumbu karang yang potensial sehingga dijadikan salah satu daerah tujuan utama wisata bahari di kawasan Taman Nasional Laut Bunaken bagian Selatan, khusus untuk kegiatan penyelaman. Dengan adanya wilayah terumbu karang yang potensial di pantai Poopoh seharusnya komunitas ikan karang Famili Pomacentridae juga akan ditemukan di wilayah ini. Sayangnya, sampai saat ini kajian komprehensif mengenai ikan karang Famili Pomacentridae di Pantai Poopoh belum ada, oleh karena itu kegiatan penelitian ini dilakukan.

Penelitian ini bertujuan untuk mengetahui distribusi dan kelimpahan ikan karang Famili Pomacentridae. Dengan dilakukannya penelitian ini diharapkan akan menghasilkan informasi ikan Pomacentridae sebagai salah satu kelompok spesies mayor ikan-ikan terumbu karang, yang dapat dipakai dalam merancang sistem pengelolaan kawasan perairan pantai Desa Poopoh lebih baik lagi, mengingat peran wilayah ini sebagai bagian Taman Nasional Bunaken.

\section{TINJAUAN PUSTAKA}

Pomacentridae adalah salah satu kelompok ikan karang tropis yang memiliki karateristik menarik. Daya tariknya tidak hanya dari corak warnanya yang cerah dan bentuknya yang agak pipih, tetapi juga dari jumlah dan aktifitasnya (Moyle dan Cech, 1998). Ikan ini terpusat di daerah Pasifik Barat dimana jumlah jenisnya akan semakin berkurang bila semakin jauh dari daerah tersebut (Allen, 1991 dalam Hukom, 1997). Beberapa contoh ikan Pomacentridae yang sudah dikenal adalah ikan anemon (anemon fish) dari genera Amphiprion dan Premnas biaculeatus (Rohmimohtarto, 2007); ikan badut (clown fish) (Lowe-McConnell, 1987), serta genera Abudefduf yang biasanya dikenal dengan nama sergeant-major (Nelson, 1984).

Bugess dan Axelrod (1973) menjelaskan bahwa famili ikan karang Pomacentridae terdiri dari 400 jenis yang termasuk dalam 25 genera. Menurut Nelson (1984) Pomacentridae terbagi dalam empat sub famili, yaitu: Sub Famili Amphiprionae; Sub Famili Chrominae; Sub Famili Lepidozyginae; dan Sub Famili Pomacentrinae.

Menurut Nelson (1984), ikan Pomacentridae memiliki bentuk tubuh yang tinggi dan pipih, mulut kecil, garis lateral tidak lengkap atau berselisihan, sirip ekor memiliki dua buah duri (sangat jarang tiga), sebuah sirip punggung dengan 9 - 4 buah duri keras dan 11-18 duri halus. Ukuran panjang maksimum ikan ini sekitar $35 \mathrm{~cm}$. Ikan Pomacentridae dewasa berwarna coklat tua, sedangkan ikan yang masih muda memiliki warna yang indah dengan garis biru sepanjang kepala hingga panggul, berukuran hingga 10 $\mathrm{mm}$. Warna biru perlahan-lahan akan menghilang saat ikan beranjak dewasa sehingga tidak ada ikan dewasa yang berwarna biru (Lythgoe dan Lythgoe, 1992). Pomacentridae adalah famili yang besar dengan kebiasaan makan yang umumnya onmivora, beberapa di antaranya adalah "plankton feeder", 
herbivora, dan ada juga pemakan invertebrata kecil yang ditemukan di terumbu karang (Bugess dan Axelrod, 1973).

Bugess dan Axelrod (1973) menjelaskan bahwa cara pemijahan semua Pomacentridae hampir sama. Ikan jantan membersihkan bagian batu karang dan membentuk suatu daerah pertahanan. Pomacentridae umumnya adalah ikan yang memiliki satu tempat tinggal tertentu, tetapi selama masa pemijahan kebanyakan dari mereka menjadi lebih agresif. Ikan jantan akan melakukan perubahan warna tubuh. Sinyal dari ikan jantan akan di tangkap oleh ikan betina yang siap memijah dengan membuat gerakan berputar di atas sarangnya. Ikan betina yang siap memijah berperan penting dalam mempertahankan tempat tinggal pada masa pemijahan. Setelah masa pemijahan selesai, ikan betina akan keluar dari sarang memberi sinyal lagi. Sekali lagi beberapa ikan betina melakukan pembiakan dengan ikan jantan, kemudian ikan jantan akan membentuk suatu pertahanan diantara telur-telur sampai mereka menetas.

\section{METODE}

\section{Tempat dan Waktu Penelitian}

Pengambilan data di lakukan di Perairan Pantai Desa Poopoh Kecamatan Tombariri, yang merupakan kawasan Taman Nasional Bunaken bagian Selatan (Gambar 1). Penelitian dilakukan di 3 lokasi yaitu, stasiun 1 (Tanjung Angkoran) berada pada $01^{\circ} 24^{\prime} 37,0^{\prime \prime}$ 'LU dan 124 $37^{\circ} 58,3^{\prime \prime} B T$; stasiun 2 (Mutiara) dengan koordinat 0124'37,1'"LU dan 124³7'59'BT, stasiun 3 (Tanjung Kelapa) yang berada pada $01^{\circ} 25^{\prime} 1.6^{\prime \prime} \mathrm{LU}$ dan $124^{\circ} 37^{\prime} 47,1$ 'BT.

\section{Bahan dan Alat}

Peralatan dan bahan yang digunakan untuk pengamatan ikhtiofauna Pomacentridae adalah peralatan, roll meter, SCUBA, sabak, alat tulis bawah air, kamera bawah air, GPS, dan Buku identifikasi. Untuk menjangkau lokasi penyelaman menggunakan perahu.

\section{Pengumpulan Data}

Pengamatan ikan Pomacentridae dilakukan dengan metode sensus visual pada transek garis. Pendataan dilakukan dengan mencatat semua spesies dan jumlah individu Pomacentridae yang ditemukan dengan radius 2,5 m ke kiri dan ke kanan (atau ke atas dan bawah) transek (English et.al., 1994).

Untuk mengidentifikasi ikan famili Pomacentridae secara visual (dalam air) adalah dengan melihat karakterkarakter morfologi eksternal seperti bentuk tubuh, pola warna. Mengikuti buku petunjuk identifikas Allen (1997), Myers (1991), Saanin (1984) dan Colin dan Arneson (1995).

\section{Analisis Data}

Untuk menentukan keanekaragaman Pomacentridae digunakan indeks Shannon-Wiener (Clarke dan Warwick, 1994), dan untuk mengevaluasi adanya dominasi jenis ikan Pomacentridae digunakan indeks dominasi Simpson (Clarke dan Warwick, 1994)

\section{HASIL DAN PEMBAHASAN}

\section{Distribusi dan Komposisi Ikan Pomacentridae}

Berdasarkan hasil identifikasi diperoleh 41 spesies yang berasal dari 12 genera yaitu, Premnas, Stegastes dan Acanthochromis masing-masing ditemukan 1 spesies, selanjutnya genera Amphiprion (5 sp), Chromis (9 sp), Dascyllus (2 sp), Abudefduf (2 sp), Amblyglyphidodon (3 sp), Chrysiptera (3 sp), Plectroglyphidodon (2 sp), Pomacentrus (10 sp), dan genera Neoglyphidodon (2 sp).

Bila membandingkan penyebaran dengan dua wilayah lainnya, pertama di perairan Selat Lembeh, BitungSulawesi Utara dimana teridentifikasi 48 spesies dari 14 genera pada 5 stasiun pengamatan (Hukom, 1997), kedua di perairan Selat Sunda (Suharti, 
1996) dari 15 stasiun pengamatan, teridentifikasi 54 spesies yang tergolong ke dalam 14 genera, maka dapat dikatakan bahwa perairan pantai desa Poopoh ini memiliki jumlah spesies yang relatif banyak.

Ada 4 spesies yang dianggap kehadirannya dalam jumlah yang besar di ketiga stasiun pengamatan yaitu, Chromis margaritifer, Pomacentrus mollucensis, Chrysiptera unimaculata dan spesies dengan jumlah individu terbesar yaitu Chromis ternatensis.

Berdasarkan kedalaman, ditemukan 35 spesies dengan total 3863 individu pada kedalaman $3 \mathrm{~m}$ dan 36 spesies di kedalaman $10 \mathrm{~m}$ dengan jumlah total 3810 individu. Sehingga dapat dikatakan bahwa distribusi ikan Pomacentridae untuk kedalaman 3 dan 10 meter berbeda hanya dari jumlah individu tiap spesies (Tabel 1). Komposisi spesies pada stasiun 1 (Tanjung Angkoran) terdiri dari 27 spesies yang berasal dari kedalaman 3 dan 10 meter, kemudian pada stasiun 2 (Mutiara) ditemukan sebanyak 20 spesies yang berasal dari kedalaman $3 \mathrm{~m}$, dan sebanyak 26 spesies dari kedalaman $10 \mathrm{~m}$. Selanjutnya pada stasiun 3 (Tanjung Kelapa) ditemukan 30 spesies pada kedalaman $3 \mathrm{~m}$ dan pada kedalaman $10 \mathrm{~m}$ sebanyak 25 spesies.

\section{Indeks Komunitas Ikan Karang Famili Pomacentridae}

Indeks Keanekaragaman adalah ukuran kekayaan komunitas dilihat dari jumlah spesies dalam suatu kawasan, beserta jumlah individu dalam tiap spesies. Indeks keanekaragaman ikan Pomacentridae berkisar antara 2.1812.857 , terendah pada kedalaman $3 \mathrm{~m}$ di stasiun 2 (2.181) dan tertinggi pada kedalaman $10 \mathrm{~m}$ di stasiun $1(2,584)-$ (Tabel 2). Dengan kisaran nilai $\mathrm{H}^{\prime}$ ini, kestabilan komunitas ikan karang family Pomacentridae sedang, karena sesuai dengan criteria penilaian jika $1<\mathrm{H}^{\prime}<$ 3 , keanekaragaman sedang, kestabilan komunitas sedang.

Nybakken (1990) menjelaskan bahwa keanekaragaman spesies tinggi, merupakan petunjuk lingkungan yang nyaman dan stabil, sedangkan nilai keanekaragaman yang rendah menandakan lingkungan yang menyesakkan dan berubah-ubah.

Nilai dominasi berkisar antara 0-1, dimana semakin besar nilainya maka terdapat kecenderungan spesies tertentu mendominasi populasi (Ludwig dan Reynolds, 1988). Kriteria penilain komunitas dengan kisaran indeks dominasi : $0,00<D \leq 0,50=$ Dominasi Rendah; $0,50<D \leq 0,75=$ Dominasi Sedang; $0,75<D \leq 1,00=$ Dominasi Tinggi. Dengan kisaran 0,081 - 0,197, nilai indeks dominasi di semua stasiun dan kedalaman dikategorikan Rendah.

Berdasarkan nilai indeks keanekaragaman dan indeks dominasi, maka proporsi jumlah individu setiap spesies memiliki kesempatan yang relatif sama dalam ekosistem terumbu karang sebagai habitatnya. Walaupun belum dikaji, kondisi ini menandakan bahwa niche (ruang) wilayah terumbu karang Desa Poopoh relatif luas, dan variasi habitat (komponen terumbu karang) relatif beragam.

\section{KESIMPULAN}

Berdasarkan hasil analisis data, secara umum dapat disimpulkan bahwa wilayah terumbu karang Desa Poopoh Kecamatan Tombariri memiliki potensi ikan karang termasuk di dalamnya Famili Pomacentridae. Kondisi ini terlihat dalam jumlah spesies maupun kelimpahan individu yang cukup tinggi dan terdistribusi hampir merata di semua stasiun pengamatan dan kedalaman.

Kestabilan komunitas ikan karang Famili Pomacentridae dalam kawasan terumbu karang Desa Poopoh Kecamatan Tombariri cukup tinggi dengan melihat nilai indeks keanekaragaman yang cukup tinggi dan indeks dominasi yang rendah. . 


\section{DAFTAR PUSTAKA}

Allen G. 1997. Marine Fishes of Tropical Australia and South East Asia. A Field Guide for Angler and Diver. Western Australia Museum

Bugges W. E., and H. R. Axelrod. 1973. Fishes of Southern Japan and Ryukyus 2nd Edition. T.F.H. Publications, Inc, Ltd. England.

Clarke K. R., and R. M. Warwick. 1994. Change in Marine Communities: an Approach to Statistical Analysis and Interpretation. Natural Environment Research Council. U.K.

Dahuri R., J Rais., S. P. Ginting, M.J. Sitepu. 2004. Pengelolaan Sumberdaya Wilayah Pesisir dan Lautan Secara Terpadu. PT. Pradnya Paramita. Jakarta.

English, S.,C. Wilkinson, and V. Baker 1994. Survey Manual For Tropical Marine Resources. Australian Institute of Marine Science. Townsville.
Hukom, F. D. 1997. Distribusi Spasial Ikan Karang (Family Pomacentridae) di Perairan Selat Lembeh, Bitung - Sulawesi Utara . Prosiding Seminar Kelautan Lembaga IImu Pengetahuan Indonesia dan Universitas Hasanudin. Ambon.

Lowe-McConnell, R. H. 1987. Ecological Studies in Tropical Fish Communities. Cambridge University Press.

Lythgoe, J., and G. Lythgoe. 1992. Fishes of The Sea; The North Atlantic and Mediterranean. The MIT Press. Cambridge, Massachusetts.

Moyle, P. B., and J. J. Cech, Jr. 1998 Fishes; An Introduction to Ichthyology 2nd Edition. Prentice Hall, Englewood Cliffs. New Jersey.

Nelson, J.S. 1984. Fishes of The World. A Wiley Interscience Publication.

Nybakken, J.W. 1992. Biologi Laut: Suatu Pendekatan Ekologis. PT. Gramedia. Jakarta. 
Tabel 1. Jumlah Spesies dan Jumlah Individu Ikan Karang Famili Pomacentridae

\begin{tabular}{|c|r|r|r|r|r|r|}
\hline \multirow{2}{*}{ Parameter } & \multicolumn{2}{|c|}{$\begin{array}{c}\text { Tanjung } \\
\text { Angkoran }\end{array}$} & \multicolumn{2}{c|}{ Mutiara } & \multicolumn{2}{c|}{$\begin{array}{c}\text { Tanjung } \\
\text { Kelapa }\end{array}$} \\
\cline { 2 - 7 } & \multicolumn{1}{c|}{$3 \mathrm{~m}$} & \multicolumn{1}{c}{$\mathbf{m}$} & $\mathbf{3 m}$ & $\mathbf{1 0 m}$ & $3 \mathrm{~m}$ & \multicolumn{1}{c|}{ 10m } \\
\hline \hline $\begin{array}{c}\text { Jumlah } \\
\text { individu }\end{array}$ & 1041 & 1187 & 849 & 1636 & 1973 & 987 \\
\hline $\begin{array}{c}\text { Jumlah } \\
\text { spesies }\end{array}$ & 27 & 27 & 20 & 26 & 30 & 25 \\
\hline
\end{tabular}

Tabel 2. Indeks Komunitas Pomacentridae

\begin{tabular}{|c|c|c|c|c|c|c|}
\hline \multirow{2}{*}{$\begin{array}{c}\text { Indeks } \\
\text { Komunitas }\end{array}$} & \multicolumn{2}{|c|}{$\begin{array}{c}\text { Tanjung } \\
\text { Angkoran }\end{array}$} & \multicolumn{2}{c|}{ Mutiara } & \multicolumn{2}{c|}{$\begin{array}{c}\text { Tanjung } \\
\text { Kelapa }\end{array}$} \\
\cline { 2 - 7 } & $3 \mathrm{~m}$ & $\mathbf{1 0 m}$ & $\mathbf{3 m}$ & $\mathbf{1 0 m}$ & $3 \mathrm{~m}$ & $10 \mathrm{~m}$ \\
\hline \hline$\left(\mathrm{H}^{\prime}\right)$ & 2.584 & 2.857 & 2.181 & 2.326 & 2.458 & 2.766 \\
\hline$(\mathrm{C})$ & 0.120 & 0.093 & 0.155 & 0.197 & 0.117 & 0.081 \\
\hline $\begin{array}{l}\mathrm{H}^{\prime}=\text { Indeks Keanekaragaman Shannon Weaner; } \\
\mathrm{C}=\text { Indeks Dominasi Simpson }\end{array}$ \\
\hline
\end{tabular}

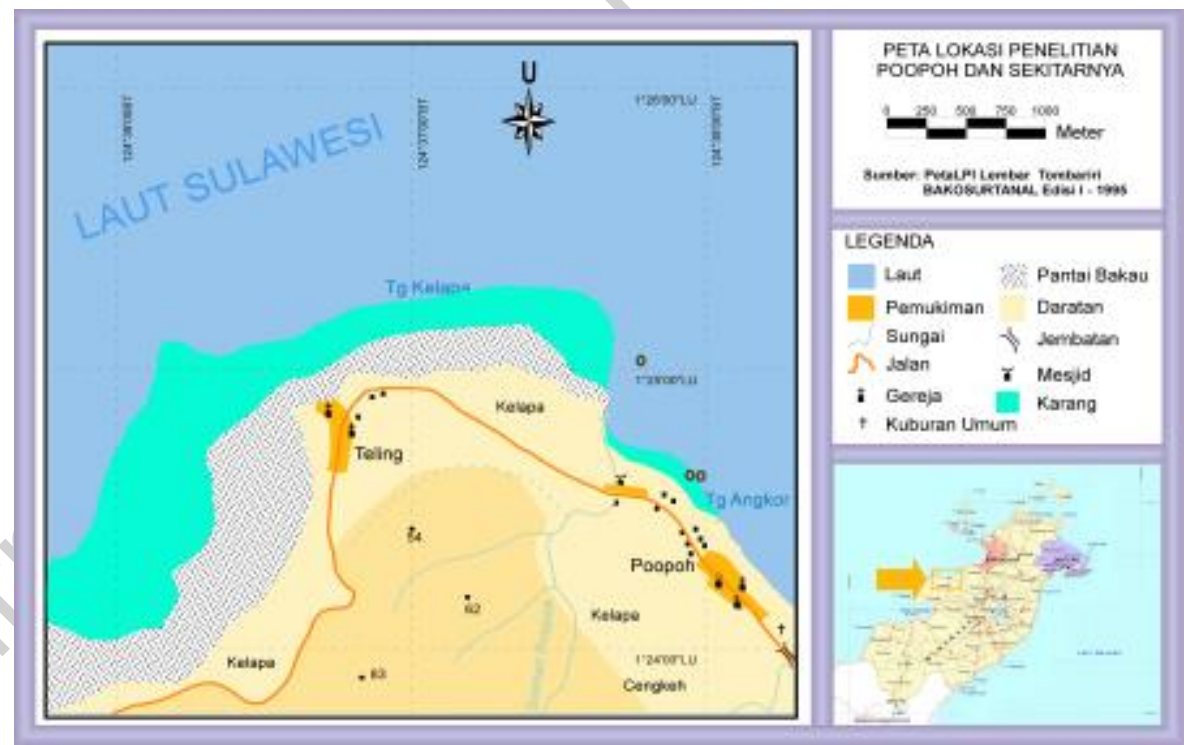

Gambar 1. Lokasi Penelitian 